\title{
Stability analysis of caverns excavated in heterogeneous salt formations
}

\author{
S. Nazary Moghadam ${ }^{1}$, H. Mirzabozorg ${ }^{1}$, A. Noorzad ${ }^{2}$ and K. Nazokkar ${ }^{3}$ \\ ${ }^{1}$ Civil Engineering Department, K.N. Toosi University of Technology, No. 1346, Valiasr Street, Mirdamad Intersection \\ 19967, P.O. Box. 15875-4416, Tehran, Iran \\ ${ }^{2}$ Faculty of Water and Environmental Engineering, Power and Water University of Technology, Tehran, Iran \\ ${ }^{3}$ Civil Engineering Department, Islamic Azad University, Central Tehran Branch, Tehran, Iran \\ saeed_nazarimoghadam@yahoo.com,mirzabozorg@kntu.ac.ir, noorzad@pwut.ac.ir, kimianazokkar@gmail.com
}

\begin{abstract}
In this paper, the influence of the presence of non-salt interbeds in the vicinity of salt caverns on the stability of the caverns was investigated. In order to describe the time-dependent inelastic behavior of rock salt, an empirical viscoplastic creep model bounded by a diagnostic failure criterion was utilized. The creep model is then implemented in a finite element program to analyze the stability of a storage cavern excavated in a salt formation interspersed with a non-salt interbed. Finally, stress distribution in the salt formation and time-dependent closure of the cavern obtained by the finite element analyses are presented and interpreted.
\end{abstract}

Keywords: Rock salt, Underground cavern, Viscoplasticity, Creep, Finite element analysis.

\section{Introduction}

The underground caverns excavated in salt formations have provided valuable storage capacity for petroleum products and hazardous chemical wastes. The major factor playing a vital role in a secure underground storage is the stability of the underground caverns which is dependent on the inelastic time-dependent or creep behavior of rock salt. Rock salt surrounding an underground cavern exhibits progressive time-dependent in elastic movement which may lead to significant or even full closure of the cavern, and also stress relaxation can be encountered around the cavern up to small ultimate stresses which may lead to the failure of the surrounding rock salt and instability of the salt cavern. In addition, in the case of heterogeneous salt formations which are interspersed with non-salt sedimentary interbeds, the time-dependent mechanical properties of interbeds have significant influence on the stability of the underground caverns. Since the non-salt interbeds show slower timedependent movements than the neighboring rock salt formation, considerable shear stresses develop in the interbeds which may bring about the failure of the interbeds. Consequently, in the case of heterogeneous salt formations, the creep behavior of non-salt interbeds should be considered in the stability of the underground caverns.

So far, several viscoplastic constitutive models have been employed to describe the creep behavior of rock salt. Among these constitutive models, the empirical creep model of rock salt developed for the Waste Isolation Pilot Plant known as the WIPP creep model (Herrmann et al., 1980a, 1980b) has been utilized extensively in the stability analysis of salt caverns. However, the WIPP creep model cannot describe the failure behavior of the rock salt realistically, and also it neglects the inelastic volume changes which occur during the creep of rock salt. In this regard, Cristescu (1993) presented a procedure to determine a general Research article (C)Indian Society for Education and Environment (iSee) viscoplastic constitutive equation which describes the creep behavior together with irreversible volume changes and failure of the rock-type materials, and also he developed a constitutive model to describe the creep of rock salt. In another research, Jin and Cristescu (1998) formulated a viscoplastic constitutive model for transient creep of rock salt and they employed the model to analyze the stress distribution around a plane strain borehole excavated in rock salt using a finite element procedure. Paraschiv-Munteanu and Cristescu (2001) derived a semi-analytical procedure based on finite element discretization for the analysis of stress variation during creep of rock salt around a plane strain borehole which describes transient and steady state creep as well as failure of the rock salt. Moreover, within the same framework, investigations of Yahya et al. (2000), Peric and Crook (2004) and Heusermann et al. (2003) are worth mentioning.

The objective of the present paper is to propose a procedure for stability analysis of underground caverns excavated in heterogeneous salt formations interspersed with non-salt interbeds. The WIPP creep model of rock salt is combined with the short-term failure criterion proposed by Cristescu and then the resulting elastoviscoplastic constitutive model is employed by a finite element code to analyze the stability of the salt caverns. Also, the creep behavior of the non-salt interbeds is described by the developed constitutive model using some modifications in the material parameters. Finally, the effect of the non-salt interbed thickness on the stability of the underground cavern is investigated.

\section{Constitutive model of rock salt}

The time-dependent inelastic behavior of rock salt is described using the WIPP viscoplastic constitutive model. Also, as the time intervals considered in this paper are in a range that steady state creep is dominant, transient creep is neglected. In this section it is assumed that compressive stresses and strains are positive while

\footnotetext{
"Caverns"

http://www.indjst.org
}

S. Nazary Moghadam et al. Indian J.Sci.Technol. 
tensile stresses and strains are negative. The constitutive equations are written in terms of engineering stress $\sigma$ and strain $\boldsymbol{\varepsilon}$ which are written in vector form as follows:

$$
\begin{aligned}
& \sigma^{T}=\left\{\sigma_{x}, \sigma_{y}, \sigma_{z}, \tau_{x y}, \tau_{y z}, \tau_{x z}\right\} \\
& \varepsilon^{T}=\left\{\varepsilon_{x}, \varepsilon_{y}, \varepsilon_{z}, \varepsilon_{x y}, \varepsilon_{y z}, \varepsilon_{x z}\right\}
\end{aligned}
$$

The constitutive functions are defined in terms of stress invariants, namely mean stress $\sigma_{m}$ and the second deviatoric stress invariant $j_{2}$ 'defined as

$$
\begin{aligned}
& \sigma_{m}=\frac{\sigma_{x}+\sigma_{y}+\sigma_{z}}{3} \\
& \sigma^{\prime T}=\left\{\sigma_{x}-\sigma_{m}, \sigma_{y}-\sigma_{m}, \sigma_{z}-\sigma_{m}, \tau_{x y}, \tau_{y z}, \tau_{x z}\right\} \\
& j_{2}^{\prime}=\frac{1}{2}\left({\sigma_{x}^{\prime 2}}^{2}+{\sigma_{y}^{\prime 2}}^{2}+{\sigma_{z}^{\prime 2}}^{2}\right)+\tau_{x y}{ }^{2}+\tau_{y z}{ }^{2}+\tau_{x z}{ }^{2}
\end{aligned}
$$

Where $\sigma$ denotes the deviatoric stress vector. In addition, the octahedral shear stress $\tau$ and the effective stress $\sigma_{\text {eff }}$ are defined by the following equations:

$\tau=\frac{\sqrt{2}}{3} \sigma_{\text {eff }}=\sqrt{\frac{2}{3}} \sqrt{j_{2}^{\prime}}$

It is assumed that the total strain $\varepsilon$ can be decomposed into an elastic part $\boldsymbol{\varepsilon}_{e}$ and a viscoplastic part $\boldsymbol{\varepsilon}_{v p}$, and therefore the total strain can be expressed as

$\varepsilon=\varepsilon_{e}+\varepsilon_{v p}$

As only the steady state creep is considered in this paper, Eq. (7) can be rewritten in the rate form as

$\dot{\varepsilon}=\dot{\varepsilon}_{e}+\dot{\varepsilon}_{v p}=\dot{\varepsilon}_{e}+\dot{\varepsilon}_{v p}^{S t}$

where over-dot represents time rate of change and the superscript $S t$ indicates steady state. The failure criterion is defined as the locus of maximum values of octahedral shear stresses determined with standard triaxial tests in relative short time intervals. The following equation proposed by Jin and Cristescu (1998) has been used to represent the shortterm failure surface.

$\tau_{f}=\gamma_{1}-\gamma_{2} \exp \left(-\gamma_{3} \frac{\sigma_{m}}{\sigma_{*}}\right)$

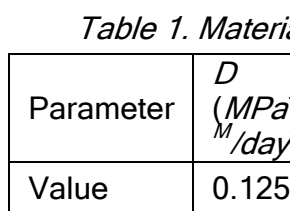

In this equation, $\tau_{f}$ is the octahedral shear stress at failure, $\gamma_{1}, \gamma_{2}$ and $\gamma_{3}$ are material constants and $\sigma_{*}$ is the unit stress. In addition, the parameter short-term failure ratio, i.e. $S F R$, is defined as the ratio of the current octahedral shear stress to the failure octahedral shear stress as follows:

$$
S F R=\frac{\tau(t)}{\tau_{f}}
$$

Finally, the WIPP steady state creep flow rule utilized in this paper is defined by the equation bellow:

$$
\dot{\varepsilon}_{v p}^{S t}=\frac{d \varepsilon_{v p}^{S t}}{d t}=\frac{3}{2}\left[D \sigma_{e f f}^{M} e^{-\frac{Q}{R T}}\right]\left(\frac{\sigma^{\prime}}{\sigma_{e f f}}\right)
$$

Vol. 5 No. 8 (August 2012) ISSN: 0974- 6846

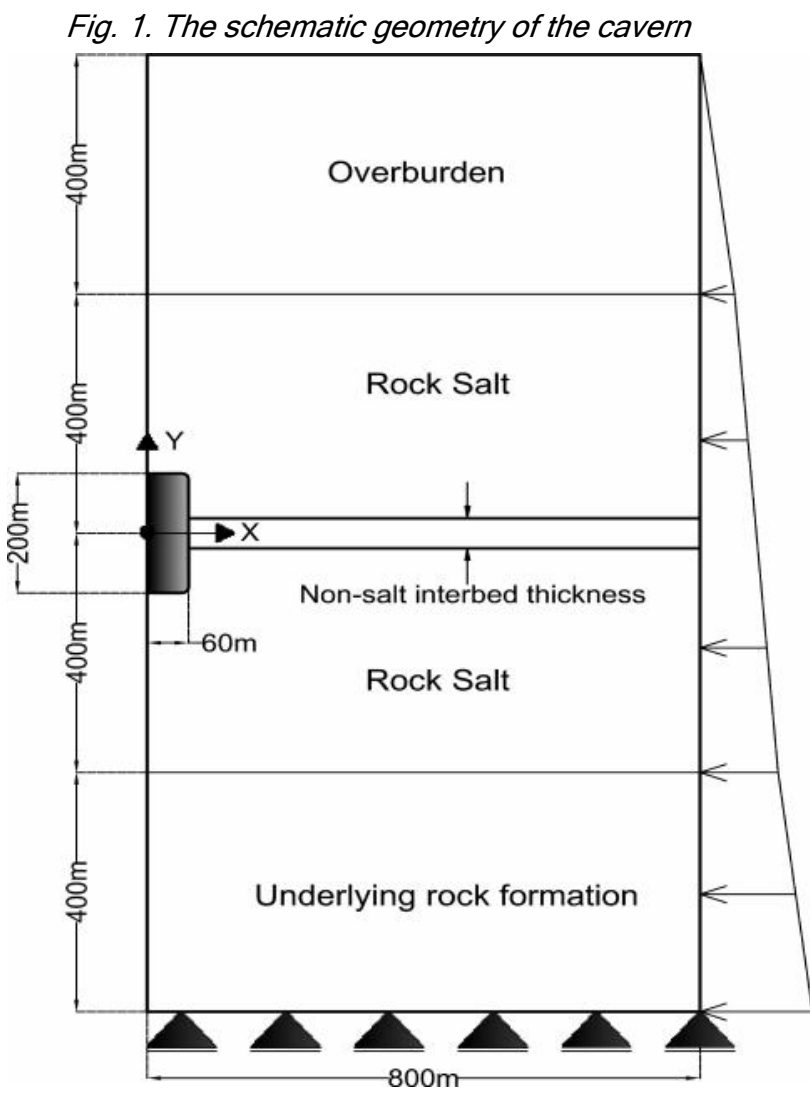

Where $D$ and $M$ are material constants, $R$ is the universal gas constant, $Q$ is the activation energy and $T$ is the temperature in degrees Kelvin $(K)$.

Finite element analysis results

The elasto-viscoplastic constitutive model presented in the previous section is employed by a finite element code to analyze the stability of a cavern excavated in a salt formation interspersed with a non-slat interbed. In 
Fig. 2. Finite element configuration of the cavern (a) $10 \mathrm{~m}$ interbed thickness (b) $50 \mathrm{~m}$ interbed thickness (c) $100 \mathrm{~m}$ interbed thickness

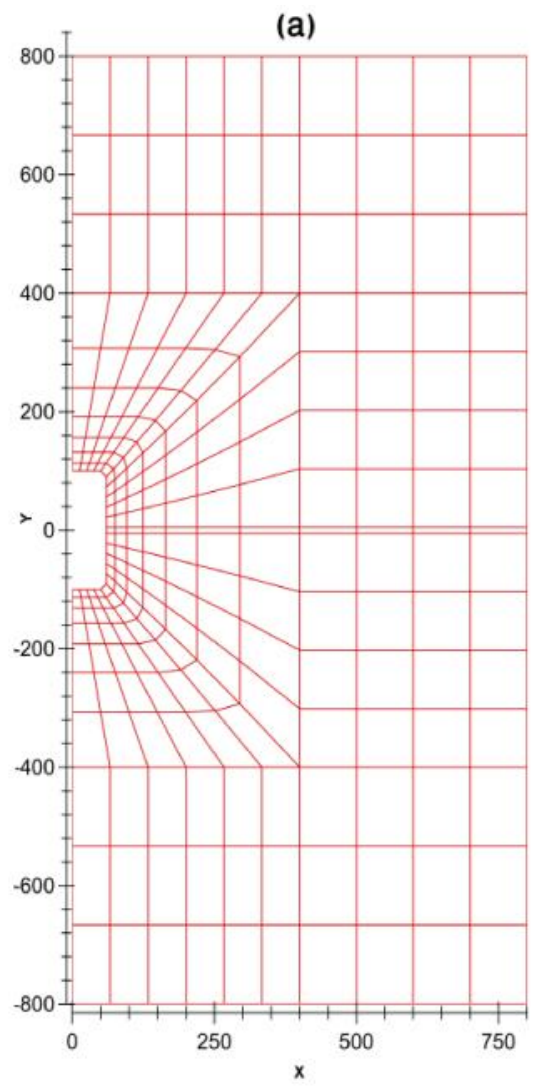

(b)

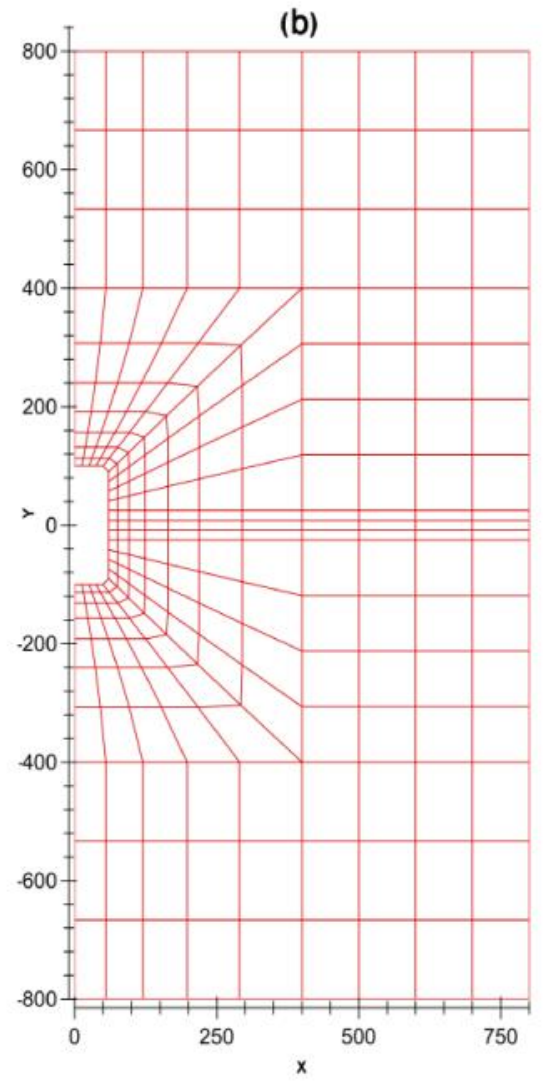

(c)

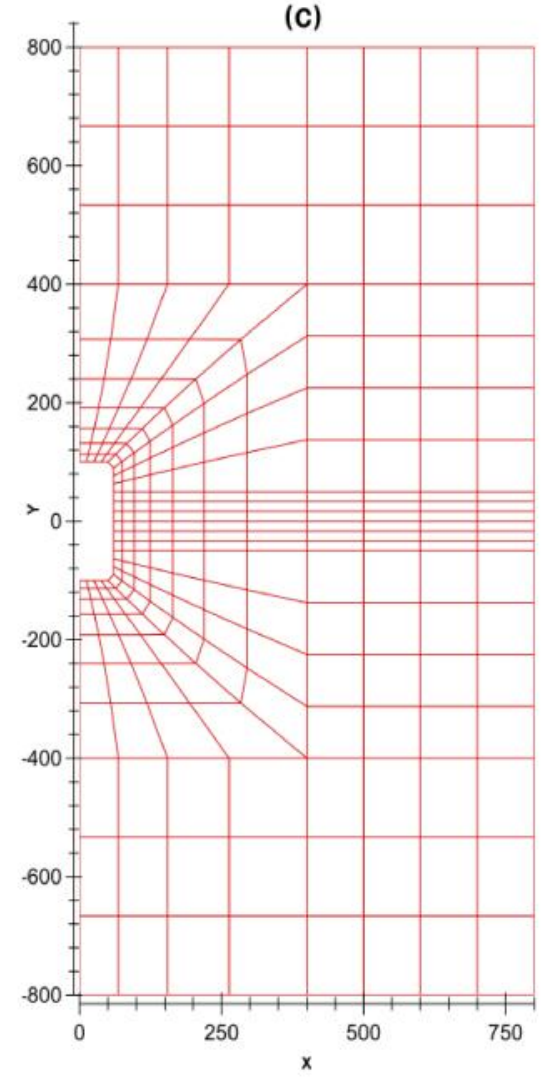

The material properties for the WIPP creep model are presented in Table 1, and also elastic modulus, Poisson's ratio and the density of the rock salt along with non-salt formations are given in Table 2. Moreover, the non-salt formations exhibit significant creep behavior even though these formations creep at lower rates than rock salt. Therefore, for simplicity, the creep model used for rock salt with second order of magnitude lower steady state creep rate than that of rock salt is utilized to represent the time-dependent behavior of the non-salt formations.

The stability analyses results are presented in Table 3 for both cases of $p=0$ and $p=5 \mathrm{MPa}$. Also, Fig. 3 (a-c) show the SFR contour for $p=5 \mathrm{MPa}$ at time $t=30$ years and the variation with time of the cavern relative closure, i.e. the ratio of the cavern's volume reduction to the cavern's initial volume, is plotted in Fig. 4.

Table 2. Material properties for rock salt and non-salt formations

\begin{tabular}{|l|c|c|c|}
\hline \multicolumn{1}{|c|}{ Material } & $\begin{array}{c}\text { Elastic } \\
\text { Modulus }(\mathrm{MPa})\end{array}$ & $\begin{array}{c}\text { Poisson's } \\
\text { ratio }\end{array}$ & $\begin{array}{c}\text { Density } \\
\left(\mathrm{kg} / \mathrm{m}^{3}\right)\end{array}$ \\
\hline Rock salt & 31 & 0.38 & 2200 \\
\hline Overburden & 22 & 0.25 & 2500 \\
\hline $\begin{array}{l}\text { Underlying rock } \\
\text { formation }\end{array}$ & 50 & 0.20 & 2500 \\
\hline
\end{tabular}

\begin{tabular}{|c|c|c|c|}
\hline $\begin{array}{c}\text { Ton-salt } \\
\text { interbed } \\
\text { thickness }(m)\end{array}$ & $\begin{array}{c}\text { Internal } \\
\text { Pressure } \\
(M P a)\end{array}$ & Time $($ day $)$ & Max SFR \\
\hline 10 & 0 & 3101.896 & 1.027 \\
\hline 10 & 5 & 11059.179 & 0.556 \\
\hline 50 & 0 & 2742.346 & 1.018 \\
\hline 50 & 5 & 11025.789 & 0.376 \\
\hline 100 & 0 & 4529.563 & 1.029 \\
\hline 100 & 5 & 11008.490 & 0.369 \\
\hline
\end{tabular}
although for greater interbed thicknesses up to about 50 $m$ the cavern stability maintain for shorter periods of time, for interbed thicknesses greater than about $50 \mathrm{~m}$ the instability of the cavern occurs later as the interbed thickness increases. In addition, it can be observed that, a greater interbed thickness brings about a wider domain with greater SFR value distributing along horizontal directions which can lead to the migration of the stored material and occurrence of hazardous events. It should also be mentioned that, due to stress relaxation around the cavern surface the rate of relative closure of the cavern decreases steadily, and also in the case of thicker non-salt interbeds the underground cavern shows slower relative closure. 
Fig. 3. SFR contour (a) $10 \mathrm{~m}$ interbed thickness (b) $50 \mathrm{~m}$ interbed thickness (c) $100 \mathrm{~m}$ interbed thickness

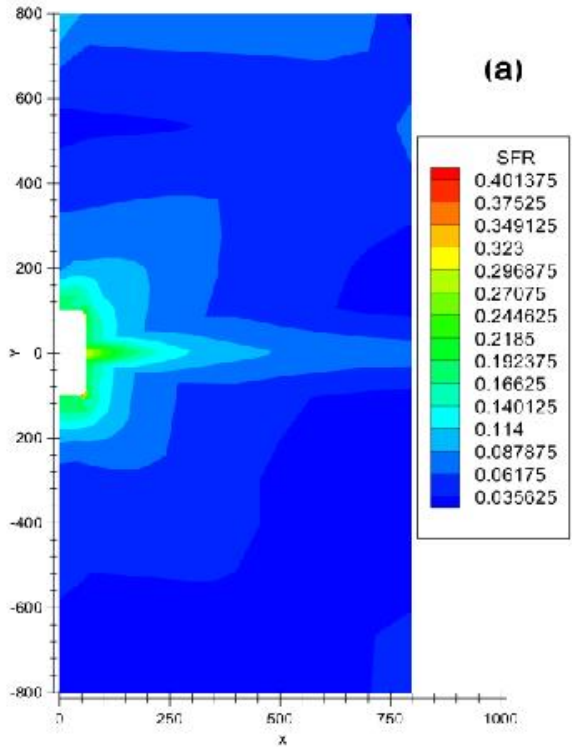

Fig.4. Variation with time of the cavern relative closure

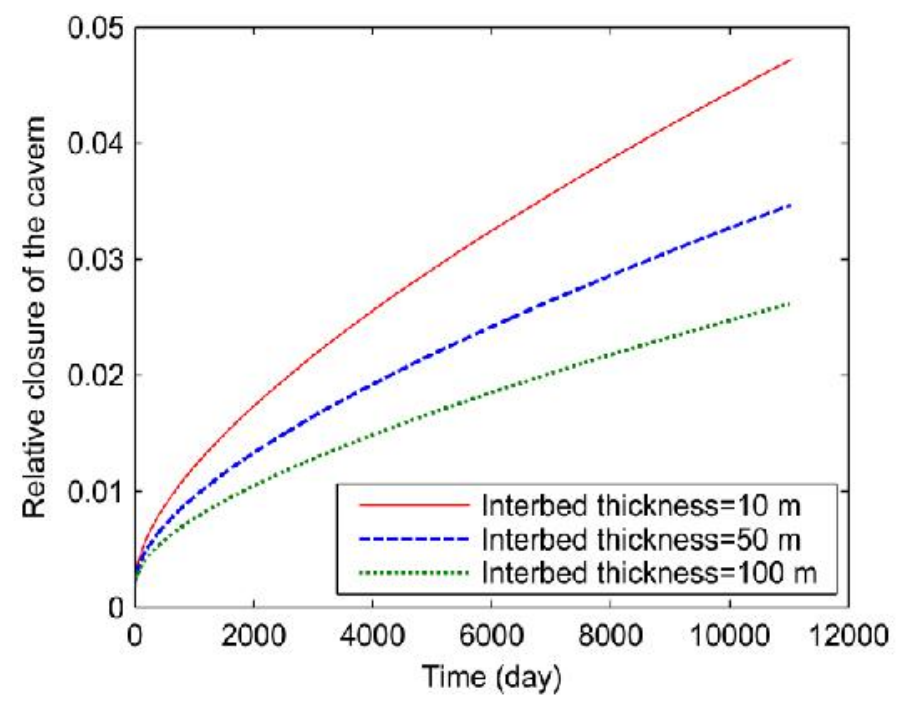

\section{Conclusions}

In the present paper, stability analysis of an underground cavern excavated in a salt formation interspersed with a non-slat interbed has been performed for different non-salt interbed thicknesses using a viscoplastic constitutive model comprising of WIPP model and Cristescu's failure criterion. The constitutive model has been implemented into a finite element code and the stress variation and ground movement during creep of rock salt around the salt cavern has been analyzed. According to the analyses, greater interbed thicknesses bring about a wider domain with greater risk of failure distributing along horizontal directions which can lead to the migration of the stored material and occurrence of Research article

(C) Indian Society for Education and Environment (iSee)
"Caverns"

http://www.indjst.org

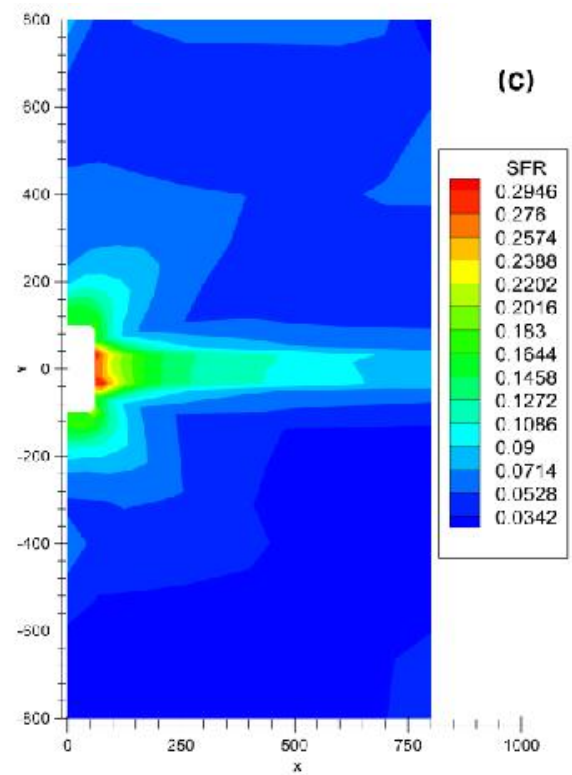

(c)

(b)

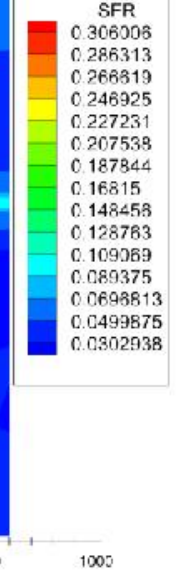

hazardous events. Also, in the case of thicker non-salt interbeds the underground cavern shows slower relative closure.

\section{References}

1. Cristescu ND (1993) A general constitutive equation for transient and stationary creep of rock salt. Int. J. Rock Mech. Min. Sci. 30, 125-140.

2. Herrmann W, Wawersik WR and Lauson HS (1980a) Analysis of steady state creep of southeastern New Mexico bedded salt. Sandia National Lab., SAND800558.

3. Herrmann W, Wawersik WR and Lauson HS (1980b) Creep curves and fitting parameters for southeastern New Mexico bedded salt. Sandia National Lab., SAND80-0558.

4. Heusermann S, Rolfs $O$ and Schmidt U (2003) Nonlinear finite-element analysis of solution mined storage caverns in rock salt using the LUBBY2 constitutive model. Comput. Struct. 81, 629-638.

5. Jin J and Cristescu ND (1998) An elastic viscoplastic model for transient creep of rock salt. Int. J. Plast. 14, 85-107.

6. Paraschiv-Munteanu I and Cristescu ND (2001) Stress relaxation during creep of rocks around deep boreholes. Int. J. Engrg. Sci. 39, 737-754.

7. Peric D and Crook AJL (2004) Computational strategies for predictive geology with reference to salt tectonics. Comput. Methods Appl. Mech. Engg. 193, 5195-5222.

8. Yahya OML, Aubertin M and Julien MR (2000) A unified representation of the plasticity, creep and relaxation behavior of rocksalt. Int. J. Rock Mech. Min. Sci. 37, 787-800. 